УДК 616.31:378

DOI $10.21661 / \mathrm{r}-465131$

А.Н. Пашков, О.В. Мячина, Л.Г. Величко

ОЦЕНКА СПЛОЧЕННОСТИ В УЧЕБНЫХ ГРУППАХ СТУДЕНТОВ СТОМАТОЛОГИЧЕСКОГО ФАКУЛЬТЕТА ВГМУ ИМ. Н.Н. БУРДЕНКО

Аннотация: в статье приведены данные по изучению сплоченности у 115 студентов стоматологического факультета ВГМУ. В ходе исследования выявлено, что студенты имеют высокую и среднюю благоприятность психологического климата. 99 из них отмечают средний уровень групповой сплоченности, а у 16 выявлен низкий уровень данного показателя. Для улучшения учебного процесса и межличностных отношений эти результаты необходимо учитывать при формировании групп.

Ключевые слова: групповая сплоченность, психологический климат, студентын.

\author{
A.N. Pashkov, O.V. Myachina, L.G. Velichko
}

\title{
COHESION ASSESSMENT OF STUDENT GROUPS FROM THE FACULTY OF DENTISTRY AT BURDENKO VORONEZH STATE MEDICAL UNIVERSITY
}

Abstract: the article presents data on the study of the cohesion of 115 students from the faculty of dentistry at Burdenko Voronezh State Medical University. The study revealed that students have high and medium favorable psychological climate. 99 of them have the average level of group cohesion, and 16 revealed a low level of this indicator. To improve the educational process and interpersonal relations, these results must be taken into account when forming groups.

Keywords: group cohesion, psychological climate, students.

Актуальность. Сплоченность группы имеет важное значение в процессе обучения, является одной из основных характеристик студенческого коллектива. Особенно это актуально для студентов первого курса, которым приходится 
адаптироваться к учебному процессу, друг другу в группе, новым условиям проживания и быта. Под сплоченностью следует понимать схожесть представлений одногруппников в убеждениях, стремлении к взаимным межличностным отношениям и в единстве практической деятельности. Факторов, влияющих на групповую сплоченность, очень много. Среди них общие интересы и приоритеты, престижность избранной профессии, взаимозависимость и т. п. По своей направленности сплоченность коллектива может быть как положительной, т.е. ориентированной на достижение цели и задач его учебной или трудовой деятельности, так и отрицательной, направленной на достижение иных целей, противоречащих общественным. С течением времени атмосфера в коллективе может меняться, поэтому сплоченность студентов является очень важным фактором, дающим возможность лучше учиться и поддерживать общение в коллективе на уровне доверительных отношений. Общий эмоциональный настрой, возникающий в группе в процессе совместного обучения и общения, формирует психологический климат, который при благоприятном варианте проявляется оптимистическим настроем, радостью общения, доверием, чувством комфорта и взаимной поддержкой у студентов [2, с. 128].

Целью исследования явилось изучение сплоченности в учебных группах 1 курса стоматологического факультета ВГМУ, выявление группы с наиболее благоприятным психологическим климатом для совместной учебы.

Mатериальл и методыл. В исследовании приняли участие студенты 1 курса стоматологического факультета. Это 115 человек в возрасте от 17 до 21 года, распределенные деканатом в 7 групп. Участникам было предложено ответить на 2 теста, включающие 23 взаимодополняющие друг друга вопросы для большей достоверности ответов [1, с. $243 ; 3$, с. 126].

Первый тест, изучающий психологический климат в группе, представляет из себя опросник с двумя колонками с противоположными по смыслу суждениями. В левой колонке - варианты, соответствующие признакам здорового психологического климата, в правой - их антипод каждого суждения. Оценивание 
проводилось по 5 бальной шкале. Итоговые показатели психологического климата суммировались.

- высокой благоприятности психологического климата соответствуют показатели в диапазоне 42-65 баллов;

- средней благоприятности - 31-41 балл;

- незначительной благоприятности - 20-30 баллов;

- показатели менее 20 баллов свидетельствуют о неблагоприятном психологическом климате.

Второй тест на оценку сплоченности группы включал 8 психологических характеристик. Тестируемые выбирали одно из трех предлагаемых утверждений, которое, по их мнению, отражает состояние группы. Результаты сплоченности оценивались в баллах по 100-бальной шкале.

Высокий уровень групповой сплоченности - 76-100 баллов.

Средний уровень групповой сплоченности - 46 - 75 баллов.

Низкий уровень групповой сплоченности - 30-45 баллов.

Критический уровень групповой сплоченности - ниже 30 баллов.

Результаты исследования. Согласно полученным данным в 1 группе (C101) из 17 опрошенных студентов 15 имели показатели психологического климата от 31 до 65, что соответствует высокому или среднему значению. Только 2 студента отмечали неблагоприятный психологический климат и имели показатели менее 30 баллов. Средний результат группы - 49,64 балла говорит о высоком уровне психологического климата. Во втором тесте 15 тестируемых имели высокий или средний уровень групповой сплоченности, что соответствует 46100 баллам, в то время как низкий уровень (0-45 баллов) имели только 2 студента (что полностью подтверждает результаты 1 тестирования). Средний результат группы - 68,82, что говорит о средней сплоченности коллектива. В своих ответах студенты с низкими показателями сплоченности и психологического климата отмечали, что чувствуют себя одинокими среди остальных участников коллектива. 
В ходе первого тестирования во 2ой группе (C-102) было выявлено отсутствие отрицательных результатов: $100 \%$ участников имели показатели, соответствующие высокому или среднему уровню. Общий итог по группе - 44,64, что свидетельствует о высокой благоприятности психологического климата. По результатам второго теста отмечено, что 14 из 17 студентов имели высокий или средний уровень сплоченности, что соответствует 46-100 баллам. А 3 из 17 опрошенных недовольны сплоченностью группы и имеют низкий или критический уровень (0-45 баллов). Средний результат - 59,86 - что говорит о среднем уровень групповой сплоченности. Трое участников тестирования, имеющие низкий уровень сплоченности, в своих ответах сходились на мнении, что в группе проявляется безразличие к эмоциональному общению. Можно сделать вывод, что им не хватает внимания в коллективе.

По результатам исследования 3 груnnы (C-103) все участвующие (100\%) считали, что в группе высокий или средний уровень благоприятности психологического климата, что соответствует 31-65 баллам. Средний результат - 43,05 высокая благоприятность. Однако во втором тесте 9 участников имели низкий или критический уровень групповой сплоченности, что соответствует 0-45 баллам. Остальные 8 участников имели высокий или средний уровень данного показателя (46-100 баллов). Полученное среднее значение - 40,47 - свидетельствует о низком уровне групповой сплоченности. Причем студенты первой подгруппы (9 человек) по результатам тестирования отмечали, что «в случае неприятностей пытаются свалить вину друг на друга или найдут виноватого», а «нервозность, явная или скрытая раздражительность окрашивают их отношения».

Из 16 опрошенных 4 группь (C-104) 15 студентов имели показатели психологического климата от 31 до 64, что соответствует среднему или высокому уровню психологического климата, и лишь 1 студент отмечал незначительную благоприятность климата. Средний результат группы - 38,35 - средняя благоприятность психологического климата. Во втором тестировании 12 студентов имели высокий уровень групповой сплоченности (46-100 баллов), в то время как 
у 4 студентов этот показатель находился на низком или критическом уровне, что соответствует 0-30 баллам. Средний результат - 55,22 - средний уровень групповой сплоченности. Проанализировав ответы в группе C-104, мы пришли к выводу, что «их староста - лидер, полностью справляется со своими обязанностями и активно участвует в жизни группь. Но есть также студенты, способности и интересы которых ещуе не раскрытыл».

Проведя тестирование в 5 группе (C-105) мы увидели, что 100\% опрошенных имели средний или высокий уровень психологического климата. Средний результат группы - 47,43 говорит о высоком уровне психологического климата. Во втором тесте 10 участников имели средний или высокий уровень групповой сплоченности, что соответствует 46-100 баллам. Остальные 6 студентов имели низкий или критический уровень этого показателя, что соответствует 0-45 баллам. Среднее значение - 57,95 - средний уровень групповой сплоченности. Самым волнующим вопросом в тестировании было утверждение о дружбе в данной группе. Большинство опрошенных считали, что «в основном студенты дружат отдельными группами, общего для всех не получается».

По данным 1го тестирования 6 груnnь (C-106) из 16 опрошенных 15 имели средний или высокий уровень психологического климата, в то время как 1 - низкий уровень данного показателя, что соответствует 0-30 баллам. Среднее значение - 47,52 - высокая благоприятность психологического климата. По результатам 2 тестирования 10 участников имели показатели психологического климата от 46 до 100, что соответствует среднему или высокому уровню групповой сплоченности. Оставшиеся 6 участников согласно полученным данным имели низкий или критический уровень групповой сплоченности. Средний результат - 50,22 говорит о среднем уровне групповой сплоченности. В 106-С группе большинство участников на вопрос «Отношение к старосте» отвечали либо нейтральное, либо «староста не справляется с управлением коллективом».

По данным первого тестирования в 7 группе (C-107) 100\% опрошенных имели средний или высокий уровень психологического климата, что соответствует 31-65 баллам. Средний результат - 47,52. Во втором тесте 11 участников 
имели показатели психологического климата 46-100 баллов, что соответствует высокому или среднему уровню групповой сплоченности. Остальные 5 участников имели низкий или критический уровень изучаемого показателя, что соответствует 0-45 баллам. Средний результат - 53,81 - средний уровень групповой сплоченности. 5 участников тестирования, имеющие низкий уровень групповой сплоченности, отметили, что некоторые из них «хотели бы поменять группу».

\section{Заключение}

1. Проведенное нами двойное тестирование дополняет друг друга, так как полученные в ходе него результаты схожи, причем исследование групповой сплоченности оказалось более информативным.

2. Выявлено, что 6 групп (99 человек) из 7 (115 человек) имеют высокую благоприятность психологического климата, в одной группе (C-104) отмечена его средняя благоприятность. Результаты представлены на рисунке 1.

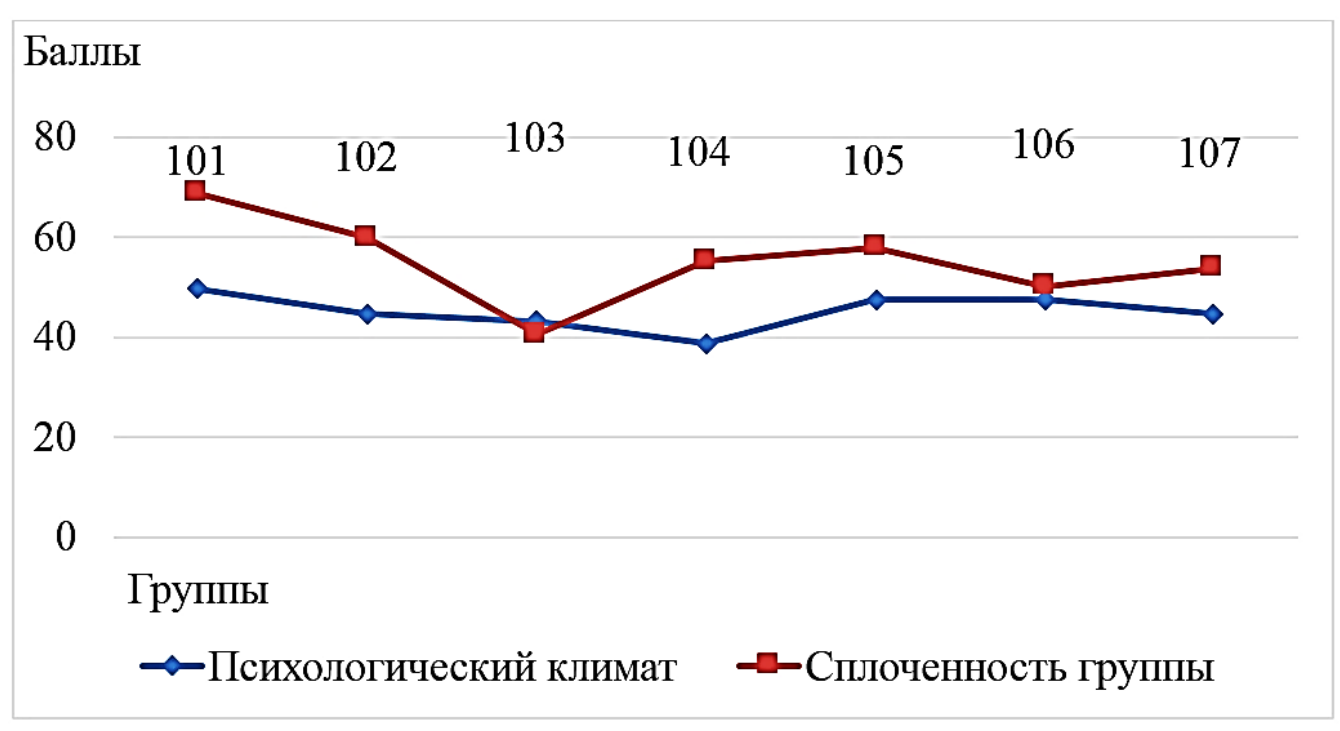

Рис. 1. Групповая сплоченность

3. В результате исследования сплоченности студенческого коллектива было выявлено, что 6 групп из 7 имеют средний уровень групповой сплоченности, и лишь одна (C-103) - низкий уровень данного показателя.

4. На наш взгляд при формировании групп следует обратить внимание на переживания студентов, связанные со студенческой жизнью, потому что положительный психологический климат и высокий уровень групповой 
сплоченности благоприятно воздействуют не только на межличностные отношения обучающихся, но и влияют на улучшение учебного процесса.

\section{Список литературы}

1. Карелин А.А. Большая энциклопедия психологических тестов / А.А. Карелин. - М: Эксмо, 2007. - 416 с.

2. Крысько В.Г. Социальная психология: учебник для бакалавров / В.Г. Крысько. - 4-е изд., перераб. и доп. - М.: Юрайт, 2016. - 553 с.

3. Фетискин Н.П. Социально-психологическая диагностика развития личности и малых групп / Н.П. Фетискин, В.В. Козлов, Г.М. Мануйлов. - М.: Изд-во Института Психотерапии, 2002. - 338 с.

Пашков Александр Николаевич - д-р биол. наук, профессор, зав. кафедрой биологии ФГБОУ ВО «Воронежский государственный медицинский университет им. Н.Н. Бурденко» Минздрава России, Россия, Воронеж.

Pashkov Alexander Nikolaevich - doctor of biological sciences, professor, head of Biology Department at Burdenko Voronezh State Medical University, Russia, Voronezh

Мячина Ольга Владимировна - канд. мед. наук, доцент, доцент кафедры биологии ФГБОУ ВО «Воронежский государственный медицинский университет им. Н.Н. Бурденко» Минздрава России, Россия, Воронеж.

Myachina Olga Vladimirovna - candidate of medical sciences, associate professor, associate professor of Biology Department at Burdenko Voronezh State Medical University, Russia, Voronezh.

Величко Лиана Григорьевна - канд. мед. наук, ассистент кафедры биологии ФГБОУ ВО «Воронежский государственный медицинский университет им. Н.Н. Бурденко» Минздрава России, Россия, Воронеж.

Velichko Liana Grigoryevna - candidate of medical science, assistant of Biology Department at Burdenko Voronezh State Medical University, Russia, Voronezh. 